\title{
Korrespondenzen.
}

\section{Zur Aziditätsbestimmung des Mageninhalts mittels des} Röntgenverfahrens.

Eine Erwiderung von Dr. Emmo Schlesinger.

Unter obigem Titel hat Gottwald Schwarz in No. 35 dieser Wochenschrift eine Reihe von Bemerkungen zu meiner unter gleichem Titel in No. 30 dieser Wochenschrift veröffentlichten Arbeit gemacht, die den Tatsachen nicht entsprechen.

Hierzu bemerke ich folgendes: 1. Nach eingehender Kenntnisnahme und auf Grund der beiden in No. 35 disser Wochenschrift zitierten Arbeiten von Schwarz haben schon im Jahre 1907 Holst und ich in der Straussschen Poliklinik Versuche. mit den Schwarz. schen Kapseln vorgenommen und das Material hierzu aus der von Schwarz angegebenen Apotheke bezogen. Die Behauptung von Schwarz, daß ich seine eigentliche Publikation übersehen hätte und es mir entgangen sei, daß die Fibroderm-Pepsin-Wismutkapseln als ein zuverlässiger röntgenologischer Indikator des Salzsäuregehaltes von ihm angegeben seien, ist demnach unrichtig.

2. Die Nachprüfung der Schwarzschen Methode ergab bei unseren Versuchen so ungünstige Resultate, daß wir sie nach kurzer Zeit einstellten. In einer Reihe von Fällen verließ die Kapsel trotz aller angewandten Kautelen den Magen, bevor die Beobachtung beendet war, es war damit alle Mühe und der große Zeitaufwand völlig nutzlos gewesen. Wenn man bedenkt, daß bei Anazidität ein Verweilen der Kapsel im Magen von fünf Stunden gefordert wird und daß Anazidität besonders häufig mit Hypermotilität verbunden ist, wird man sich eine Vorstellung machen können, wie oft dieses fatale Ereignis eintreten kann.

3. Schien uns die Methode theoretisch nicht genügend gestützt. $\mathrm{Um}$ nur das Wesentlichste anzuführen: Schwarz überträgt die Verdauungszeiten im Reagenzglasversuch auf die Lösung der Kapsel im Magen; dieses ist aber sicherlich für einen großen Teil der Fälle nicht zulässìg. Der Magen ist nach dem P. F. in etwa $3 / 4-1 \frac{1}{2}$ Stunden leer, die Kapsel liegt dann nicht wie im Reagenzglase inmitten einer verdauenden Flüssigkeit, sondern im leeren Magen unter Bedingungen, die im Einzelfalle garnicht zu eruieren sind.

Nur die unter 2 und 3 angeführten Uebelstände und Bedenken und nicht ,unvollständige Kenntnisnahme des Sachverhaltes" haben mich veranlaßt, in meiner oben zitierten Arbeit zu sagen, daß die Schwarzschen Kapseln sich mir nicht bewährt haben; ich muß an diesem Urteil über die Schwarzsche Aziditätsbestimmung trotz der Empfehlung, zu der Schwarz in No. 35 dieser Zeitschrift Gelegenheit nimmt, auch jetzt noch festhalten. ${ }^{2}$ ) 